\title{
Research on the cultivation of College Students' intercultural communicative competence based on the technology of multimedia immersion in 5G Era
}

\author{
Yong Zhang ${ }^{1, *}$ \\ ${ }^{1}$ School of Business Administration, Wuhan Business University, WuHan, Hubei, 430000, China
}

\begin{abstract}
One belt, one road initiative, China needs comprehensive talents with international vision, international working background, international finance and international economic management. In order to improve college students' intercultural communicative competence, China attaches importance to foreign cultural exchange and comprehensively improves the cultivation of foreign communicative competence. Students' awareness of cross-cultural communication is weak and their communicative competence is lacking. In addition to enriching students' cross-cultural communication ability, it is urgent to cultivate students' comprehensive language competence. The rapid changes and development of economic globalization and information technology have promoted the frequent communication between different cultures. Such a development trend also puts forward higher requirements for the talent training of university teaching at this stage. The teaching of each university pays more attention to the application ability of language knowledge and the ability of international communication and communication in the future work and social communication. In the actual teaching process, due to the lack of practical communicative situations, most of the teaching still stay in the aspects of historical and cultural background, mode of thinking, pragmatic principles, values and social norms of different nationalities, and there are few opportunities to experience the coding and decoding in actual communication, and the related obstacles and misunderstandings in the process are even more difficult to understand. Therefore, cross-cultural practice should be placed on the same important position as the cognition of language and culture knowledge. Combined with the rapid development of network information technology, the creation of optimized teaching and practice integration paradigm has become the research and development trend of cultivating cross-cultural communication ability in today's information society.
\end{abstract}

\section{Introduction}

$5 \mathrm{G}$ is the fifth generation mobile communication technology. The Ministry of industry and information technology officially issued $5 \mathrm{~g}$ business license on June 6 , 2019, which means the first year of $5 \mathrm{~g}$ business in China. According to the "5g economic and social impact white paper" issued by China Communications Research Institute, $5 \mathrm{~g}$ technology has the ability to provide a peak rate of at least 10 times that of $4 \mathrm{G}$, a transmission delay of millisecond and a connection capacity of 100 million. This kind of ability not only represents the evolution of communication technology, but also means that the communication era will have more powerful information release ability and data hyperlink function, which has a more profound impact than any previous technology change.

As a key buzzword in the field of communication technology, $5 \mathrm{~g}$ is not a simple " $4 \mathrm{G}+1 \mathrm{~g}$ ". $5 \mathrm{~g}$ has the technical characteristics of high-speed, low delay and linking everything. It can more effectively solve the problems of stuck, limited capacity and more realistic virtual scene in the process of communication, and realize the technology experience of "everything is transmitted, all inclusive and everything connected". With the establishment of $5 \mathrm{~g}$ communication base station in China, $5 \mathrm{~g}$ is getting closer and closer to us. 5g's powerful information release ability and data link function indicate that we have been in the era of intelligent media dominated by immersion communication. At the same time, the technical innovation of $5 \mathrm{~g}$ architecture is constantly deepening. One person is not only the sender but also the receiver of information. Communication has become people-centered, and the "immersed person" in the immersion communication has become the pronoun of the current audience. Furthermore, the immersion communication created by $5 \mathrm{~g}$ technology meets people's multi-dimensional needs. In this era of immersive communication, human behavior and characteristics will have new changes, which are constrained by communication technology, and also affect the reshaping of communication environment. 


\section{Intercultural communicative competence}

The process of communication between people with different cultural backgrounds is intercultural communication. In 1972, hymes, an American anthropologist and sociolinguist, put forward the concept of communicative competence. He believed that in addition to linguistic competence, people also need another kind of competence, namely "communicative competence". In other words, people must understand what is appropriate and what is not appropriate in social communication, and be able to improve the language they use according to the factors of topic, situation and interpersonal relationship In the early 1980s, Canale and Swain proposed that communicative competence should be a system of three abilities: grammatical competence, sociolinguistic competence and strategic competence.

Intercultural communication competence is a complex concept. It contains many elements and involves many levels. Different scholars have given different understandings. Bennett, Bennett \&amp; Alien believe that intercultural communication competence includes three meanings: the ability to transcend ethnocentrism, the ability to appreciate other cultures, and the ability to perform appropriately in one or more cultural environments According to samovar and Porter, intercultural communication competence is divided into three aspects: motivation, knowledge and skills. Gao Yihong thinks that intercultural communication competence is the ability or quality required for successful intercultural communication. She also points out that the cultivation of intercultural communication competence in China should be centered on cultural awareness.

Intercultural communication competence (ICC), also known as intercultural competence (IC), cannot be simply equated with linguistic competence. Researchers have divided the elements and levels of ICC from different perspectives. Spitzberg and Cupach; samovar and porter

(2004) divides ICC into three aspects: consciousness, knowledge and skills, which is widely recognized by many scholars in intercultural communication research. Awareness refers to the willingness to communicate; knowledge refers to the cognition of communicators to cultural variables ranging from nation to nation, country to individual; skills are the ability to achieve the purpose of cross-cultural communication and communication. Gudykunst divides ICC into eight aspects: empathy, self behavior adjustment, ambiguity tolerance, interaction control, relational behavior, expression of respect, knowledge seeking tendency and communicative attitude. Es] Byram's ICC framework from the perspective of culture and language teaching has been widely used in foreign language teaching. He believes that in addition to social language ability and discourse ability, crosscultural ability formed by the interaction of cultural awareness and contact skills, discovery and interaction skills is an important factor in determining the success of communication. Chen Guoming from the early proposed four levels of communication skills, personality strength, psychological adjustment ability and cultural awareness, to the three interdependent cognitive, emotional and behavioral levels, all of which provide powerful reference for the cultivation of ICC.

Jia Yuxin believes that ICC consists of four parts: basic communicative competence, plot competence, communicative strategy, and emotional and relational competence. The basic communicative competence refers to the necessary linguistic, cultural and cognitive abilities, which are the basis for individuals to achieve their communicative purposes; the plot competence system includes the ability to follow the plot in general sense and the ability to surpass the logic and behavior rules followed by oneself; the communicative strategy refers to the remedial measures and measures taken when communication fails or fails to reach the goal; emotional and relational competence It refers to the ability to use empathy correctly and flexibly in the process of communication. Yang Ying and Zhuang Enping (2007) tried to discuss the construction of ICC framework, including global awareness, and formed a practical competence framework in teaching together with knowledge cognition, communication practice and cultural adjustment. Wen Qiufang distinguishes ICC from IC and believes that ICC includes intercultural competence and communicative competence. In the process of communication, communicative competence refers to the content of language, pragmatics and strategy; tolerance, sensitivity and flexibility are important components of cross-cultural competence. In theory, this structure provides a strong support for foreign language teaching aiming at improving intercultural communicative competence.

From the elaboration of Chinese and foreign scholars, we find that intercultural communication competence should be the ultimate goal of communication in the process of language communication. As shown in Figure 1, language and cultural knowledge and communication skills are the basis for improving cross-cultural communication ability. The practice scene of crosscultural communication is the space for the two to be used and practiced. The combination of the three can achieve effective communication, that is, to achieve the established goal of cross-cultural communication. As shown in Figure 1.

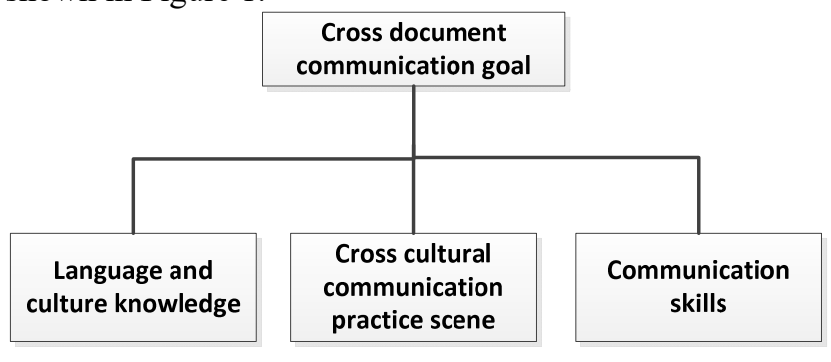

Figure 1 the components of ICCC 


\section{Cultivating college students' intercultural communicative competence under the environment of multimedia and network}

Influenced by the traditional examination oriented education in China, the examination results of school bar, as the main content of teaching quality, ignore the cultivation of students' cross-cultural communication ability; lack of introduction of cultural background knowledge, students can not fully understand the customs and cultural background of Britain and the United States. Because students are in a closed language learning environment, they have little contact with the people of the language they study, lack of real language environment and experience the real cultural background. Due to the restriction of the old teaching concept, teaching content and traditional classroom teaching mode, as well as teachers' weak cross-cultural awareness, students' intercultural communication ability is not paid attention to.

With the wide application of multimedia network technology, multi-media information technology is used to connect cross-cultural teaching and provide learners with a new way and environment for learning. Compared with the traditional teaching methods, the teaching mode based on multimedia network under the guidance of constructivism theory has many advantages. Constructivism is an important branch of cognitive learning theory. The basic view of constructivism is that in the process of interaction with the surrounding environment, individuals gradually construct the knowledge about the external world, so as to obtain their own cognitive structure Development, which emphasizes the role of learners' social, cultural and historical background in the cognitive process, holds that individual learning is carried out in a certain historical and social cultural background, and society can play an important role in supporting and promoting the development of individual learning. In other words, language input is actually the learner's active construction. Through the original language knowledge system and the new language, the language input is the learner's active construction Constructivism teaching mode emphasizes the students as the main body, creating a rich information environment conducive to language construction and reconstruction for students, so that students can obtain more language knowledge in limited classroom learning. The technical characteristics of multi-media and network provide material for the realization of constructivism teaching mode The basic and technical support make the basic attributes of learning environment such as "situation", "cooperation", "conversation" and "meaning construction" advocated by constructivism can be realized. Constructivism theory has changed the role of teachers. Teachers are no longer the simple presentation of knowledge, nor the authority of knowledge, but should be the active helper and guide of students to construct knowledge In order to be an active helper and guide of students' knowledge construction, teachers should stimulate students' interest in learning, arouse and maintain students' learning motivation, organize cooperative learning among students as much as possible, carry out discussion and communication, and guide the process of collaborative learning, so as to make it develop in a direction conducive to meaning construction. Constructivism theory has become an important part in deepening university teaching reform Guiding ideology.

The new version of curriculum requirements clearly states in the teaching mode that "colleges and universities should make full use of modern information technology, adopt the teaching mode based on computer and bilingual classroom, and improve the single teaching mode dominated by teachers. The new teaching mode is not limited by time and place, and is developing in the direction of personalized and autonomous learning." in such an environment, language Through multimedia and network communication and display, cultural information can effectively inspire the formation and development of students' image thinking and innovative thinking, which is conducive to enhancing cultural awareness, developing cross-cultural communication ability and improving comprehensive language quality.

Multimedia teaching environment is a combination of picture, text, sound, light and color. It has rich expressive power. Making use of its advantages, it can make the teaching content three-dimensional and diversified. In order to cultivate college students' cross-cultural communication ability, teachers should connect language teaching with cultural teaching by means of multimedia teaching platform, and develop cross-cultural awareness and ability at the same time of language teaching Classroom teaching is the teacher's main position. In the teaching process, teachers can choose the recording, courseware, DVD and video materials related to the text content to guide students to attach importance to cultural learning, familiarize themselves with cultural phenomena and cultural connotations in language learning, learn to compare, find out similarities and differences, and improve the quality of teaching The sensitivity of cultural differences can improve the comprehensive language quality; the rich information resources in multimedia can also be used to create some lively, natural and interesting cultural scenes. Students are required to perform imitation or role play according to the specific situations and the corpus provided, so that they can be integrated into the actual situation of life and experience the real use of English in realistic life practice In this way, students can not only learn authentic English, but also have more opportunities to experience. Because words, sounds and images act on students' multiple senses at the same time, it causes positive reflection of their cognitive structure. Students can quickly grasp the teaching content, improve their interest in learning, and greatly improve their learning effect Improve intercultural awareness and communicative competence.

Constructivism teaching theory holds that the creation of "learning environment" and "learning atmosphere" is also very important for the construction of the meaning of individual learners. At present, university teaching vigorously advocates the popularization and application of educational technology with multimedia network as the core in schools. One of the purposes is to improve the efficiency of teaching activities and cultivate students' 
autonomous learning ability Vocabulary is the basis of mastering any basic language skills and conducting crosscultural communication. In learning vocabulary, students can be guided to make use of network corpus resources to achieve a certain cultural context Students are encouraged to watch more original British and American movies so as to understand the culture of English speaking countries. Students can also be guided to read western English literary works, newspapers and magazines online Magazines and current affairs reviews can absorb cultural knowledge, increase cultural accomplishment, broaden Western cultural vision and improve cross-cultural communication ability.

In the multimedia network environment, the combination of multimedia classroom teaching and network autonomous learning teaching mode should not only pay attention to language teaching, but also strengthen cultural teaching, effectively help students construct cross-cultural communication knowledge, strive to create a real language communication environment, cultivate students' strong cross-cultural awareness, so as

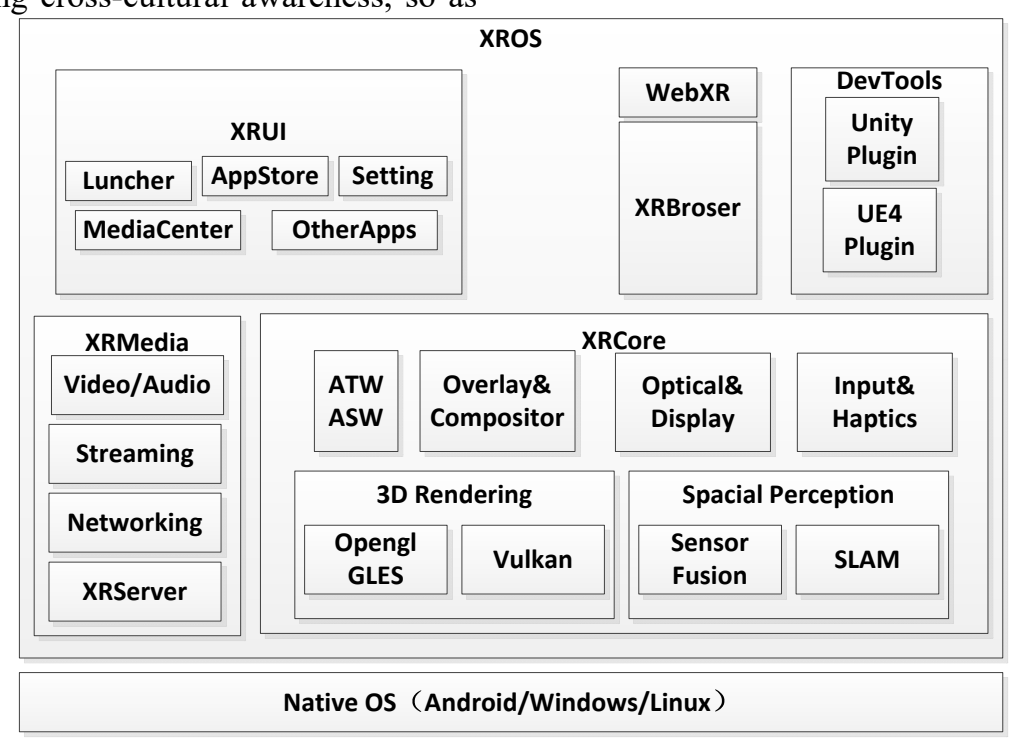

Figure 2 multimedia immersion architecture

In the higher education stage of education and teaching, teachers should pay attention to create a scientific and efficient teaching atmosphere, and guide students to actively integrate into computer learning. Teachers should also pay attention to the production of multimedia courseware in multimedia teaching, use multimedia to show vivid teaching situation in front of students, attract students' learning attention, enable students to think and explore better, and cultivate students' learning literacy. Teachers should also use multimedia courseware to stimulate students' learning initiative in education and teaching, and timely improve the dominant position of students, and guide students to better improve their personal quality in active exploration and thinking.

Because some teachers think that multimedia teaching technology is to reduce the burden of their own teaching, so they do not use multimedia courseware In the long run, it is difficult for teachers to inspire students to establish a scientific concept of development in education and to achieve the cultivation of students' cross-cultural communication ability And improve.

\section{Application of multimedia immersion technology in college intercultural communication competence}

Due to the rich skills of multimedia operation, teachers should put in a certain amount of energy in the process of making multimedia courseware, think deeply about the problems that students encounter in learning in advance, and combine with the teaching content to deeply excavate teaching materials and carry out the creation and innovation of teaching courseware. Because some teachers don't pay enough attention to the application of courseware in teaching, they don't put enough energy into the process of making courseware. The courseware is too simple and boring, which is not conducive to students' learning and development. As shown in Figure 2. 
meaning. With the development of technology, as a new way of communication, immersion communication presents in various aspects of people's life in different forms. Li Qin, a scholar, believes that immersive communication is a human-centered and open media form, including all the new and old media forms, all the tangible and intangible media forms that may produce, disseminate, display and receive information, including the environment itself, and even more, a mode of communication in which people are the media form. The mode of immersive communication includes all the forms of communication that have appeared in the past: if the media and people are more closely integrated, the boundary between mass communication and interpersonal communication will be difficult to distinguish.

\section{Acknowledgments}

In this paper, the research was sponsored by Educational Science Planning Project of Wuhan Education Bureau, and the Project Name is The Belt and Road strategy for training international talents: A Case

Study of Wuhan Business University human resource management(internationalization)experimental class(2018C082).

\section{References}

1. ZHAO W X, WANG J P, HE Y L, et al. Mining product adopter information from online reviews for improving product recommen-dation[J].ACM Transactions on Knowledge Discovery from Data, 2016, 10 (3): 29.

2. ZHOU P, ZHOU Y X, WU D P, et al. Differentially privateonline learning for cloud-based video recommendation with multi-media big data in social networks[J]. IEEE Transactions on Multimedia, 2016,18 (6): 1217 -1229.

3. MEEHAN K, LUNNEY T, CURRAN $\mathrm{K}$, et al. Aggregatingsocial media data with temporal and environmental context for recommendation in a mobile tour guide system[J].Journal of Hospitality and Tourism Technology , 2016,7 ( 3 ):281 -299.

4. ZHANG T F,MA F M. Improved rough k-means clustering algorithm based on weighted distance measure with Gaussian function[J]. International Journal of Computer Mathematics,2017, 94 (4): 663675.

5. TRAN D C, WU Z J, WANG Z L, et al. A novel hybrid dataclustering algorithm based on artificial bee colony algorithm and K-means[J]. Chinese Journal of Electronics, 2015, 24(4):694 -701. 